\title{
Crescimento de crambe na presença ou ausência de competição interespecífica
}

\author{
Germani Concenço ${ }^{1 *}$, Luiz Alberto Staut ${ }^{2}$, Igor Vinicius Talhari Correia ${ }^{3}$, \\ Luiz Carlos Yamamoto Vieira ${ }^{4}$ César José da Silva \\ http://dx.doi.org/10.1590/0034-737X201562050006
}

\begin{abstract}
RESUMO
O crambe (Crambe abysinica) tem ciclo médio de 90 dias, podendo ser utilizado como alternativa à safrinha no sistema de rotação de culturas. Torna-se necessário compreender a dinâmica de crescimento desta cultura, para que os fatores de produção possam ser manejados corretamente. Objetivou-se, com este estudo, descrever os parâmetros de crescimento das plantas de crambe, na ausência e na presença de competição interespecífica. O experimento foi instalado no outono-inverno de 2011, em Latossolo Vermelho distroférrico, em blocos casualizados, com três repetições. Os tratamentos constaram da manutenção da cultura constantemente sob competição com competidor simulado, ou na ausência de competição durante todo o ciclo. As coletas de material para a análise de crescimento foram realizadas quinzenalmente, a partir da semeadura da cultura. Foram calculados a área foliar (AF), massa seca de colmos ou caules (MSC), folhas (MSF) e total (MST), índice de área foliar (IAF), taxa de crescimento absoluto (TCA) e relativo (TCR), taxa de assimilação líquida (TAL), área foliar específica (AFE), duração de área foliar (DAF) e razão de área (RAF) e de massa (RMF) foliar da cultura, na ausência e na presença de competição, bem como do simulador de competição. A cultura do crambe apresenta baixo potencial competitivo e o efeito da competição é mais severo de 60 a 70 DAE da cultura. Além disso, pode-se inferir que o desempenho da cultura em condições de campo é diretamente descrito pela TAL, que por sua vez é altamente influenciada pela DAF e pela RMF.
\end{abstract}

Palavras-chave: Crambe abyssinica, desenvolvimento, cultura oleaginosa, interferência.

\section{ABSTRACT}

\section{Growth of crambe under presence or absence of inter-specific competition}

Crambe (Crambe abyssinica) has a cropping cycle of around 90 days, being suitable as an alternative to the second grain crop planted after soybean is harvested in the Center West region of Brazil. It is necessary to understand the growth and development dynamics of crambe plants in order to allow correct management of the production factors. This study aimed to describe the growth and development parameters of crambe plants under presence or absence of interspecific competition. The experiment was installed in the fall-winter 2011 in an Oxisoil, in completely randomized blocks design with three replications. Treatments comprised crambe plants growing either in presence or absence of interspecific simulated competition, throughout the cropping cycle. Plants were collected for the growth analysis every 15 days from harvest until 75 days after emergence. Growth parameters leaf area (AF), dry mass of stems/culms (MSC), leaves (MSF) and total (MST) dry mass, leaf area index (IAF), absolute (TCA) and relative (TCR) growth rates, net assimilation rate (TAL), specific leaf area (AFE), leaf area duration (DAF), leaf

Submetido em 30/05/2012 e aprovado em 24/08/2015.

Embrapa Agropecuária Oeste, Dourados, Mato Grosso do Sul, Brasil. germani.concenco@embrapa.br

Embrapa Agropecuária Oeste, Dourados, Mato Grosso do Sul, Brasil. luiz.staut@embrapa.br

${ }^{3}$ Embrapa Agropecuária Oeste, Dourados, Mato Grosso do Sul, Brasil. igor.vinicius@aedu.com

${ }^{4}$ Embrapa Agropecuária Oeste, Dourados, Mato Grosso do Sul, Brasil. cesar.silva@embrapa.br

*Autor para correspondência: germani.concenco@embrapa.br 
area ratio (RAF) and leaf mass ratio (RMF) were determined for the crop plants, subjected or not to competition, as well as for the simulated competitor. Crambe is a low competitive crop, being the competition more severe until 60-70 days after emergence. Besides, crop performance under field conditions was properly described by the net assimilation rate (TAL), which is also affected by the leaf area duration (DAF) and leaf mass ratio (RMF).

Key words: Crambe abyssinica, development, oilseed crop, interference.

\section{INTRODUÇÃO}

Originário da Etiópia, país africano de clima quente e seco, e domesticado na Europa, na região do Mediterrâneo, o crambe (Crambe abyssinica) pertence à família das crucíferas, a mesma da colza e da canola. Como tem ciclo médio de 90 dias, é indicado como alternativa para a safrinha, em especial para produtores de soja e de milho, no sistema de rotação de culturas.

A produção rápida, a rusticidade da cultura, o baixo custo, a fácil adaptação do plantio, a facilidade de processamento para a extração de óleo e a possibilidade de aproveitamento de máquinas e equipamentos já utilizados em outras oleaginosas, tornam o crambe adequado para a agricultura familiar, segmento econômico visto como importante produtor de oleaginosas para a produção de biodiesel (Monteiro, 2007).

$\mathrm{O}$ plantio apresenta produtividade que pode variar de 1.000 a 1.500 quilos por hectare e, do grão, o óleo corresponde de 36 a 38\% (Baez, 2007). Requer solos bem corrigidos quanto à acidez e de boa fertilidade. Com relação ao clima, é tolerante a geadas leves nos períodos mais sensíveis. O ciclo varia entre 85 e 90 dias após a emergência.

Embora esta cultura seja estudada há algumas décadas, torna-se necessário compreender sua dinâmica de crescimento, para que os fatores de produção possam ser fornecidos no momento mais crítico e os fatores ambientais inibidores do desenvolvimento possam ser compreendidos e manejados por meio da definição da época ótima de semeadura, textura e estrutura do solo, nível de umidade e requerimento hídrico da cultura.

Objetivou-se com este estudo descrever os parâmetros de crescimento das plantas de crambe, na ausência e na presença de competição interespecífica.

\section{MATERIAL E MÉTODOS}

O experimento foi instalado no outono-inverno de 2011 no campo experimental da Embrapa Agropecuária Oeste, em Dourados - MS. O solo é classificado como Latossolo Vermelho distroférrico (Embrapa, 1999), textura muito argilosa, originalmente sob vegetação de cerrado. O delineamento experimental foi o de blocos ao acaso com três repetições. As parcelas constaram de oito linhas de $5 \mathrm{~m}$ espaçadas em $0,25 \mathrm{~m}$. A área útil foi constituída pelas quatro linhas centrais. O plantio ocorreu em 26/05/2011, com semeadora-adubadora Semeato SHM-1113, regulada para profundidade de semeadura de $3 \mathrm{~cm}$. A emergência ocorreu em 02/06/2011. A adubação foi realizada com $347 \mathrm{~kg} \mathrm{ha}^{-1}$ de NPK 08-20-20. Para proporcionar competição com a cultura, previamente à semeadura da cultura, foi semeado a lanço e incorporada ao solo aveia preta (Avena strigosa) na proporção de $10 \mathrm{~kg} \mathrm{ha}^{-1}$ de sementes.

Os tratamentos constaram da manutenção da cultura constantemente sob competição com plantas de aveia (competidor simulado), ou na ausência de competição durante todo o ciclo. No tratamento sem competição, as parcelas foram capinadas semanalmente, da emergência até início da senescência da cultura, com arranquio manual das plantas de aveia presentes na linha da cultura. Nenhum tratamento fitossanitário ou adubação foi realizado após a emergência da cultura.

As coletas de material para a análise de crescimento foram realizadas quinzenalmente, a partir da semeadura, até o estádio de início de senescência, aos 15, 30, 45, 60 e 75 dias após a emergência (DAE) da cultura. Além das plantas da cultura, o competidor também foi avaliado no tratamento com presença de competição.

Em cada avaliação, as plantas da cultura e do competidor foram cortadas rente ao solo e acondicionadas em sacos de papel, levadas imediatamente ao laboratório para processamento. Em cada avaliação, plantas da cultura foram coletadas em duas subamostras de $0,5 \mathrm{~m}$ na linha por parcela $\left(0,25 \mathrm{~m}^{2}\right.$ por parcela), enquanto o competidor foi coletado em duas subamostras de $0,25 \mathrm{~m} \times 0,5 \mathrm{~m}$ na entrelinha da cultura $\left(0,25 \mathrm{~m}^{2}\right.$ por parcela).

No laboratório, as plantas foram separadas em colmos ou caules e em folhas, e, as áreas foliares da cultura e do competidor foram aferidas com equipamento de mesa Licor LI-3100. Após, os componentes foram armazenados individualmente em sacos de papel, identificados e levados a estufa com circulação forçada de ar, a $65{ }^{\circ} \mathrm{C}$, até massa constante, quando então se obteve a massa seca de caules ou colmos e de folhas, em balança eletrônica de precisão. 
Com área foliar, área de coleta, massa seca de colmos ou caules e de folhas e anotação dos dias de coleta, foram calculados a área foliar (AF), as massas secas de colmos ou caules (MSC), de folhas (MSF) e total (MST), o índice de área foliar (IAF), as taxas de crescimento absoluto (TCA) e relativo (TCR), a taxa de assimilação líquida (TAL), a área foliar específica (AFE), a duração de área foliar (DAF) e as razões de área (RAF) e de massa (RMF) foliar da cultura, na ausência e na presença de competição, bem como do simulador de competição. As fórmulas utilizadas para os cálculos podem ser encontradas em Thornley (1976), Gardner et al. (1985) e Oliveira et al. (2006). Quando fórmulas pontuais e intervalares estavam disponíveis para o cálculo do mesmo parâmetro, as pontuais foram utilizadas.

Os dados não foram submetidos à análise de variância pelo teste $\mathrm{F}$, por não cumprirem todos os pressupostos necessários e por representarem pequeno número de unidades experimentais, o que resultou em poucos graus de liberdade para o resíduo.

Os dados foram submetidos diretamente à análise de variância das regressões e descritos por equações com base em modelos lineares e não lineares, considerandose para a escolha do modelo o significado biológico do parâmetro e os valores de $\mathrm{R}^{2}$; o ajuste relativo da equação aos dados foi verificado com base na estatística não paramétrica de Kolmogorov-Smirnov (K-S), de duas amostras (observados x esperados), considerando-se para a aceitação ou não da equação o valor á de K-S > 0,05 (Massey, 1951). Todos os dados foram processados no ambiente estatístico R (R-development, 2012). As equações e os coeficientes de ajuste para todas as variáveis são apresentados na Tabela 1 .

\section{RESULTADOS E DISCUSSÃO}

A área foliar (AF) das plantas da cultura (Figura 1) foi altamente influenciada pela ocorrência do competidor. Quando livre de competição, a AF máxima das plantas de crambe ocorreu aos 68 dias após a emergência (DAE), quando cada planta da cultura apresentava em média 100 $\mathrm{cm}^{2}$ de AF. A partir deste ponto, a queda de folhas por abscisão foi acelerada, em decorrência do início do processo de senescência. Em contraponto, quando a cultura desenvolveu-se na presença do competidor, a AF máxima por planta foi de $26 \mathrm{~cm}^{2}$, aos $45 \mathrm{DAE}$; a partir desse período, o sombreamento ocasionado pela infestante foi tão severo que a cultura não foi capaz de captar radiação solar suficiente para garantir balanço fotossintético positivo e continuar emitindo novas folhas (Figura 1). O competidor, por outro lado, apresentou pico de $\mathrm{AF}$ aos $60 \mathrm{DAE}$, com $176 \mathrm{~cm}^{2}$ por planta. Quando a cultura é considerada isoladamente, observa-se que a planta da cultura foi me- nos eficiente que a do competidor no incremento de área foliar, por sua menor inclinação da curva de área foliar, em comparação com a curva do competidor (Figura 1). Salienta-se que, embora o competidor tenha sido avaliado somente na parcela onde foi semeado juntamente com o crambe, ele foi tão eficiente em inibir as plantas da cultura que praticamente inibiu seu crescimento a zero; assim seu comportamento foi igualado ao de aveia semeada isoladamente.

$\mathrm{O}$ índice de área foliar (IAF) das plantas mostrou comportamento muito similar ao da área foliar total por plantas (AF). Salienta-se que, embora o crambe livre de competição tenha sido capaz de acumular quantidades, equivalentes às do competidor, de MST ao final do ciclo, sua área foliar foi sempre inferior à do competidor, seja em termos absolutos (AF), seja em termos relativos à área avaliada (IAF).

As folhas são os órgãos responsáveis por até $90 \%$ da massa seca acumulada nas plantas, resultante da atividade fotossintética (Oliveira et al., 2007). Assim, fatores como temperaturas elevadas em períodos de estresse hídrico causam a diminuição desta variável, tornando-a indicadora sensível de estresses sofridos pela planta (Gurevitch et al., 2009). Além disso, o desenvolvimento exagerado da área foliar pode ocasionar prejuízos à produção da cultura cuja parte econômica não sejam as folhas, como observado por Oliveira et al. (2007) para cana-de-açúcar. Isto se deve ao fato de que área foliar excessiva significa alta retenção de folhas nas partes mais baixas da planta, onde a captação de luz é baixa e as taxas fotossintéticas acabam sendo negativas. Em consequência, essas folhas mais baixas acabam atuando como dreno de fotoassimilados em vez de terem o papel de fonte (Concenço et al., 2012).

A massa seca de folhas (MSF) mostrou comportamento diferenciado entre culturas isolada, sob competição, e competidora (Figura 1); quando a cultura se desenvolveu livre de competição o acúmulo de MSF foi baixo até os 50 DAE, por causa, provavelmente, do período seco característico da região onde o experimento foi instalado; a partir dos 50 DAE, a ocorrência de algumas chuvas, aliada a temperaturas adequadas propiciou ambiente adequado ao crescimento do crambe, atingindo ao redor de $300 \mathrm{~g}$ por planta de massa seca, ao final do ciclo de cultivo. Crambe cultivado na presença do competidor resultou em cerca de $25 \mathrm{~g}$ por planta de MSF, em pico coincidindo com o pico de área foliar deste tratamento (Figura 1), sendo a mesma tendência observada para o competidor (Figura 1). Para a cultura do crambe isolada, o pico de acúmulo de MSF não coincidiu completamente com a dinâmica de incremento de área foliar, indicando que alterações na espessura da lâmina foliar possam ter ocorrido. 
A massa seca de caules (MSC) aumentou de forma exponencial para a cultura do crambe cultivado isolado e para o competidor (Figura 1); a MSC do crambe cultivado na presença do competidor aumentou de forma lenta e, aos 80 DAE, os caules de plantas da cultura sob competição pesavam ao redor de $19 \mathrm{~g} \mathrm{~m}^{-2}$, enquanto, na ausência de competição, a cultura foi capaz de acumular ao redor de $265 \mathrm{~g} \mathrm{~m}^{-2}$ de MSC. Da mesma forma que o observado para área foliar, o competidor mostrou-se mais eficiente que as plantas da cultura, em cultivo isolado, em acumular MSC (Figura 1).

A massa seca total (MST) das plantas aumentou quando o crambe foi cultivado isoladamente e a aveia foi considerada como cultura isolada (por seu potencial de inibir o crescimento do crambe nas parcelas com competição), sendo que o competidor apresentou acúmulo de massa mais rápido no início do desenvolvimento, em contraponto ao crambe livre de competição, que concentrou seu acúmulo de MST mais para o final do ciclo de cultivo. Isto indica que, embora o crambe seja capaz de acumular grandes quantidades de MST, ele é menos competitivo que a aveia; isto é confirmado ao se analisar o acúmulo de MST em plantas de crambe cultivadas na presença do competidor (Figura 1). O sombreamento severo ocasionado pelo competidor resultou em baixa captação de radiação pelas plantas da cultura, baixa taxa fotossintética, balanço negativo do balanço primário da planta e paralisação do crescimento da cultura, quando comparado com o acúmulo de MST na ausência de competição.

O balanço de acúmulo de massa seca em folhas e em colmos pode indicar se a competição e o sombreamento aos quais a planta está submetida são aceitáveis, ou não, para a espécie em avaliação (Domingos et al., 2011). Aspiazú et al., (2008) observaram que plantas de capimarroz (Echinochloa crusgalli) acumularam mais massa em colmos que em folhas quando sob alta intensidade de competição, como forma de sobrepassar as plantas do competidor e formar o seu dossel acima das demais plantas. O contrário ocorreu na ausência de competição, em que o acúmulo preferencial de massa ocorreu em folhas, com fechamento do dossel mais rapidamente e maximização da captação da radiação solar. Além disso, Merrill et al., (2002) afirmam que o sistema radicular do crambe acumula mais massa, é mais agressivo e atinge maiores profundidades que o sistema de raízes de canola, feijão, soja e ervilha, sendo também alternativa para a descompactação do solo. Assim, parte da massa não acumulada na parte aérea do crambe é direcionada à maximização de captação de nutrientes no solo. Isto pode, por outro lado, tornar a cultura do crambe menos competitiva, na parte aérea, em comparação com as supracitadas.

Tabela 1: Equações e coeficientes de ajuste (estatística não paramétrica de Kolmogorov-Smirnov) para as curvas de evolução dos diferentes parâmetros avaliados, tanto nas plantas da cultura (na ausência e na presença de competição) como nas do competidor. Embrapa Agropecuária Oeste, Dourados-MS, 2011

\begin{tabular}{|c|c|c|c|c|c|}
\hline Trat. & Equação & $\mathbf{K}-\mathbf{S}^{\mathbf{1}}$ & Trat. & Equação & $\mathbf{K}^{-\mathbf{S}^{1}}$ \\
\hline $\mathrm{AF}^{2}: \mathrm{CL}^{3}$ & $Y=7,8-2,66 X+0,14 X^{2}-0,001 X^{3}$ & 0,145 & TCR:CL & $\mathrm{Y}=0,2+4,48^{*} \mathrm{e}^{\left(-0,5 *(\ln (\mathrm{x} / 62,6) / 0,03)^{\wedge} 2\right)}$ & 0,335 \\
\hline $\mathrm{AF}: \mathrm{CC}$ & $Y=-5,23+1,22 X-0,013 X^{2}$ & 0,303 & TCR:CC & $\mathrm{Y}=0,05+2,98^{*} \mathrm{e}^{\left(-0,5^{*}(\ln (\mathrm{x} / 62,3) / 0,03)^{\wedge} 2\right)}$ & 0,167 \\
\hline $\mathrm{AF}: \mathrm{CP}$ & $Y=11,8-3,0 X+, 022 X^{2}-0,002 X^{3}$ & 0,318 & TCR:CP & $\mathrm{Y}=0,32+6,13^{*} \mathrm{e}^{\left(-0,5^{*}(\ln (\mathrm{x} / 61,8) / 0,03)^{\wedge} 2\right)}$ & 0,333 \\
\hline MSF:CL & $\mathrm{Y}=\mathrm{e}^{0,075 \mathrm{X}}$ & 0,335 & TAL:CL & $Y=-1,41+0,9 X-0,03 X^{2}+0,0003 X^{3}$ & 0,183 \\
\hline MSF:CC & $Y=-4,67+0,9 X-0,01 X^{2}$ & 0,256 & TAL:CC & $\mathrm{Y}=2,29+0,31 \mathrm{X}-0,005 \mathrm{X}^{2}$ & 0,178 \\
\hline MSF:CP & $Y=4,71-1,35 X+0,15 X^{2}-0,001 X^{3}$ & 0,161 & TAL:CP & $Y=-0,03+0,6 X-0,009 X^{2}$ & 0,225 \\
\hline MSC:CL & $\mathrm{Y}=\mathrm{e}^{0,073 \mathrm{X}}$ & 0,282 & AFE:CL & $Y=259-1,4 X$ & 0,205 \\
\hline MSC:CC & $Y=1,47+0,14 X$ & 0,357 & AFE:CC & $Y=265-1,27 X$ & 0,230 \\
\hline MSC: CP & $\mathrm{Y}=\mathrm{e}^{0,077 \mathrm{X}}$ & 0,341 & AFE:CP & $Y=209-0,63 X$ & 0,186 \\
\hline MST:CL & $\mathrm{Y}=\mathrm{e}^{0,083 \mathrm{X}}$ & 0,381 & DAF:CL & $Y=-2,12+0,28 X-0,003 X^{2}$ & 0,198 \\
\hline MST:CC & $Y=5,56+0,25 X$ & 0,341 & DAF:CC & $Y=-0,34+0,09 X-0,002 X^{2}$ & 0,216 \\
\hline MST:CP & $Y=-1,99+0,93 X+0,07 X^{2}$ & 0,272 & DAF:CP & $Y=-3,03+0,55 X-0,007 X^{2}$ & 0,218 \\
\hline IAF:CL & $Y=0,11-0,04 X+0,002 X^{2}-0,001 X^{3}$ & 0,145 & RAF:CL & $Y=161-1,48 X$ & 0,244 \\
\hline IAF:CC & $Y=-0,07+0,02 X-0,0002 X^{2}$ & 0,303 & RAF:CC & $Y=156+0,55 X-0,025 X^{2}$ & 0,258 \\
\hline IAF:CP & $Y=0,17-0,04 X+0,003 X^{2}-0,0003 X^{3}$ & 0,318 & RAF:CP & $Y=137-1,1 X+0,02 X^{2}-0,0003 X^{3}$ & 0,199 \\
\hline TCA:CL & $\mathrm{Y}=\mathrm{e}^{0,041 \mathrm{X}}$ & 0,357 & RMF:CL & $\mathrm{Y}=0,45+0,01 \mathrm{X}-0,0002 \mathrm{X}^{2}$ & 0,260 \\
\hline TCA:CC & $Y=0,88-0,017 X$ & 0,243 & RMF:CC & $Y=0,55+0,01 X-0,0002 X^{2}$ & 0,272 \\
\hline TCA:CP & $Y=1,95+0,094 X$ & 0,158 & $\mathrm{RMF}: \mathrm{CP}$ & $Y=0,57+0,003 X-0,00007 X^{2}$ & 0,185 \\
\hline
\end{tabular}

${ }^{1} \mathrm{O}$ valor apresentado é o do parâmetro " $\mathrm{D}$ ” da estatística de Kolmogorov-Smirnov. A probabilidade foi maior que 5\% (p>0,05) para todas as equações apresentadas, indicando ajuste entre os dados observados no experimento e os esperados, estimados através da respectiva equação.

${ }^{2}$ AF: área foliar; MSF: massa seca de folhas; MSC: massa seca de colmos; MST: massa seca total; IAF: área foliar; TCA: taxa de crescimento absoluto; TCR: taxa de crescimento relativo; TAL: taxa de assimilação líquida; AFE: área foliar específica; DAF: duração de área foliar; RAF: razão de área foliar; RMF: razão de massa foliar.

${ }^{3}$ CL: cultura livre de competição; CC: cultura sob competição; $\mathbf{C P}$ : competidor (aveia). 
Dentre os parâmetros do crescimento, aqueles com base mais direta no incremento de matéria seca da planta são os mais adequados, dentre os quais se destacam a taxa de crescimento absoluto (TCA) e a taxa de crescimento relativo (TCR). Embora sua obtenção seja praticamente direta, muitas vezes a TCA ocasiona interpretações equivocadas da variação de crescimento do vegetal ao longo do ciclo (Larcher et al., 2004); por isso, a TCA normalmente é utilizada em conjunto com a TCR, que expressa o acúmulo de massa seca da planta, por unidade de tempo, em função da massa seca inicial no período.

A taxa de crescimento absoluto (TCA) está de acordo com o observado para MST, em que plantas da cultura livres de competição apresentaram menor TCA que a do competidor, até 40 DAE, a partir do qual a cultura apresentou maior TCA que a planta infestante; adicionalmente, a TCA do crambe sob competição diminui em relação à dos demais tratamentos desde o início do desenvolvimento, passando a ser nula a partir dos 55 DAE por
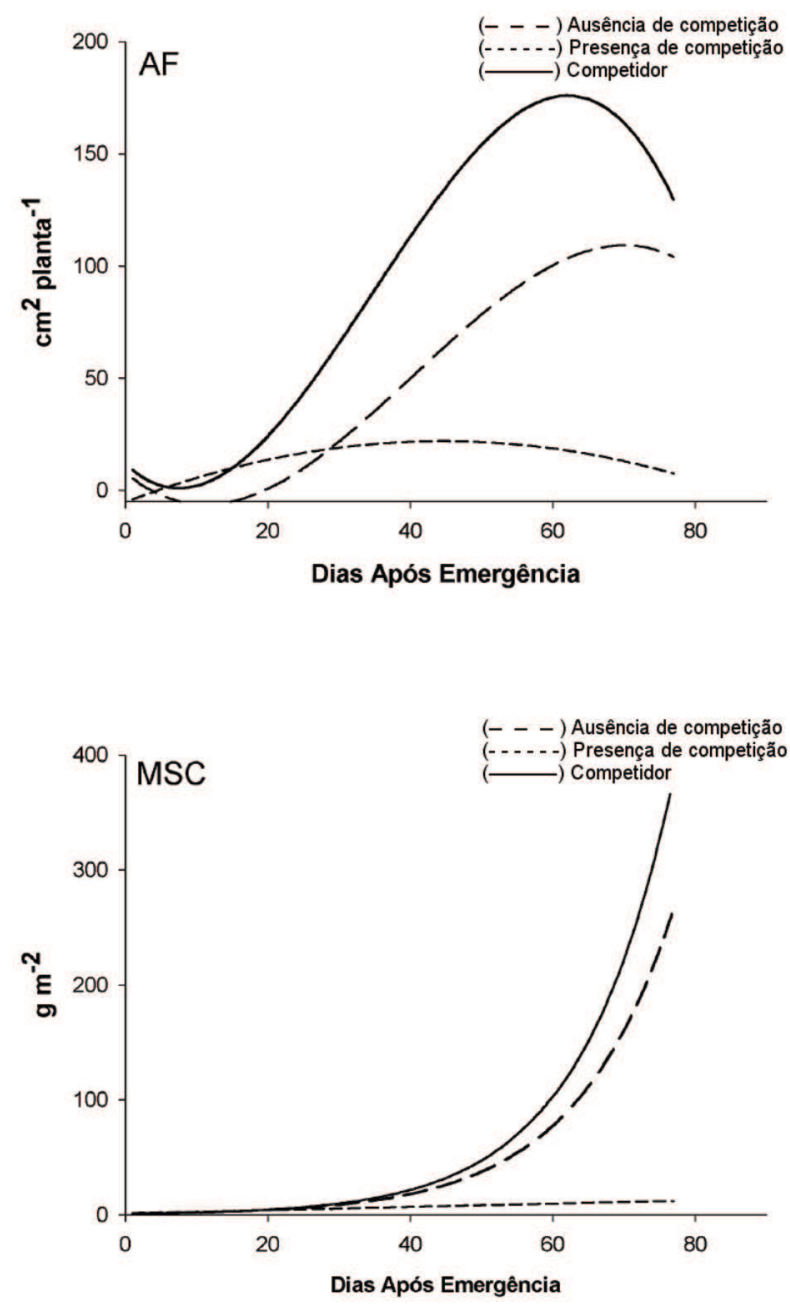

causa da forte interferência imposta pelo competidor (Figura 2). A taxa de crescimento relativo (TCR), por outro lado, manteve-se positiva e praticamente constante, da emergência até os 56 DAE, quando ocorreu um pico de crescimento acelerado para os três tratamentos, na seguinte ordem decrescente de vigor: competidor, crambe livre de competição, e crambe sob competição. Ao redor de 70 DAE, a TCR retornou às taxas anteriormente observadas (Figura 2).

Conforme demonstrado por Aguiar-Netto et al., (2000) na cultura da batata, a TCR normalmente iniciase em seu ponto máximo logo após a emergência e reduz-se gradativamente estabilizando-se no início da maturação e senescência da planta. Neste trabalho, o comportamento já discutido de estabilização da TCR, da emergência até os 55 DAE, foi atribuído à ocorrência de condições ambientais desfavoráveis (temperatura baixa, ausência de chuvas significativas no período). Atribuiu-se o pico da TCR, entre 56 e $70 \mathrm{DAE}$, à ocorrência de temperaturas adequadas ao desenvolvimento,
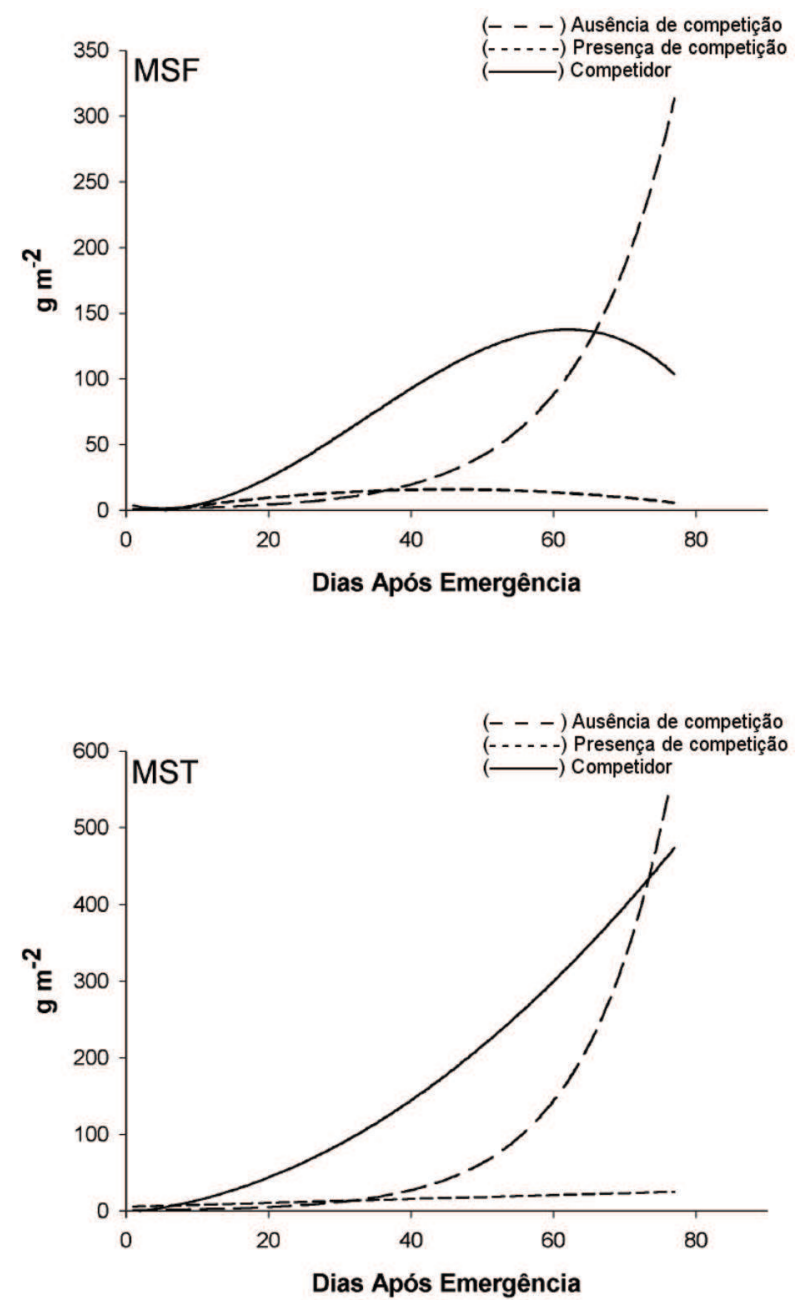

Figura 1: Área foliar (AF) e massa seca de folhas (MSF), de colmos ou caules (MSC) e total (MST) de crambe, na ausência e na presença de competição interespecífica e do competidor. Embrapa Agropecuária Oeste, Dourados-MS, 2011. 
concomitantemente com a ocorrência de chuvas, que haviam estado praticamente ausentes no período anterior a 56 DAE (Figura 2).

A taxa de assimilação líquida (TAL) reflete a dimensão do sistema assimilador que está envolvido na produção de massa seca, sendo uma estimativa da fotossíntese líquida da planta por área foliar e pode apresentar valores positivos ou negativos, em função das condições às quais a planta é submetida (Oliveira et al., 2006). A TAL foi descrita por modelo linear de segundo grau para o competidor e também para crambe na presença do competidor (Figura 2), com valores máximos de TAL de 9,8 $\mathrm{g} \mathrm{m}^{-2}$ de área foliar $\mathrm{dia}^{-1}$, aos $32 \mathrm{DAE}$, e de $6,3 \mathrm{~g} \mathrm{~m}^{-2} \mathrm{dia}^{-}$ ${ }^{1}$, aos $27 \mathrm{DAE}$, respectivamente para o competidor e para crambe sob competição. Chandranath (2006) encontrou valores de TAL entre 4,0 e 6,0 $\mathrm{g} \mathrm{m}^{-2}$ de área foliar dia $^{-1}$, para a cultura do girassol, afirmando, ainda, que a presença de uma planta daninha menos competitiva que a cultura semeada na entrelinha não influenciou de forma significativa na TAL do girassol. Isto está de acordo com Larcher (2004), que mostra que, de maneira geral, dicotiledôneas $\mathrm{C}_{3}$ apresentam TAL entre 5,0 e 10,0 g m${ }^{2}$ de área foliar dia ${ }^{-1}$. Por outro lado, Krug \& Fink (1991) encontraram TAL variando entre 0,5 e $1,3 \mathrm{~g} \mathrm{~m}^{-2} \mathrm{dia}^{-1}$, para a cultura do nabo forrageiro (Raphanus sativus).

Crambe cultivado na ausência de competição mostrou TAL acentuada, da emergência aos 20 DAE e, a partir dos 47 DAE; entre 20 e 47 DAE, a TAL da cultura do crambe manteve-se praticamente constante (Figura 2). Com base na TAL, pode-se afirmar que a aveia é mais competitiva que o crambe, pelo menos até aos $60 \mathrm{DAE}$, pois os valores de TAL da cultura sob competição foram muito inferiores aos observados para o tratamento na ausência de competição.

A área foliar específica (AFE) permite avaliar a espessura da lâmina foliar de determinado vegetal, em função do ambiente de crescimento disponível (Ferreira et al., 2008). Assim, ao se comparar os valores de AFE de plantas da mesma espécie cultivadas em ambiente ótimo e sob determinado estresse, é possível fazer inferências sobre a gravidade do estresse aplicado na anatomia do vegetal. A disponibilidade de radiação é o principal fator determinante da AFE; plantas crescidas sob luminosidade excessiva apresentarão limbo foliar mais espesso (menor AFE) do que o de plantas mantidas sob níveis de radiação adequados à espécie; o oposto ocorre com plan-
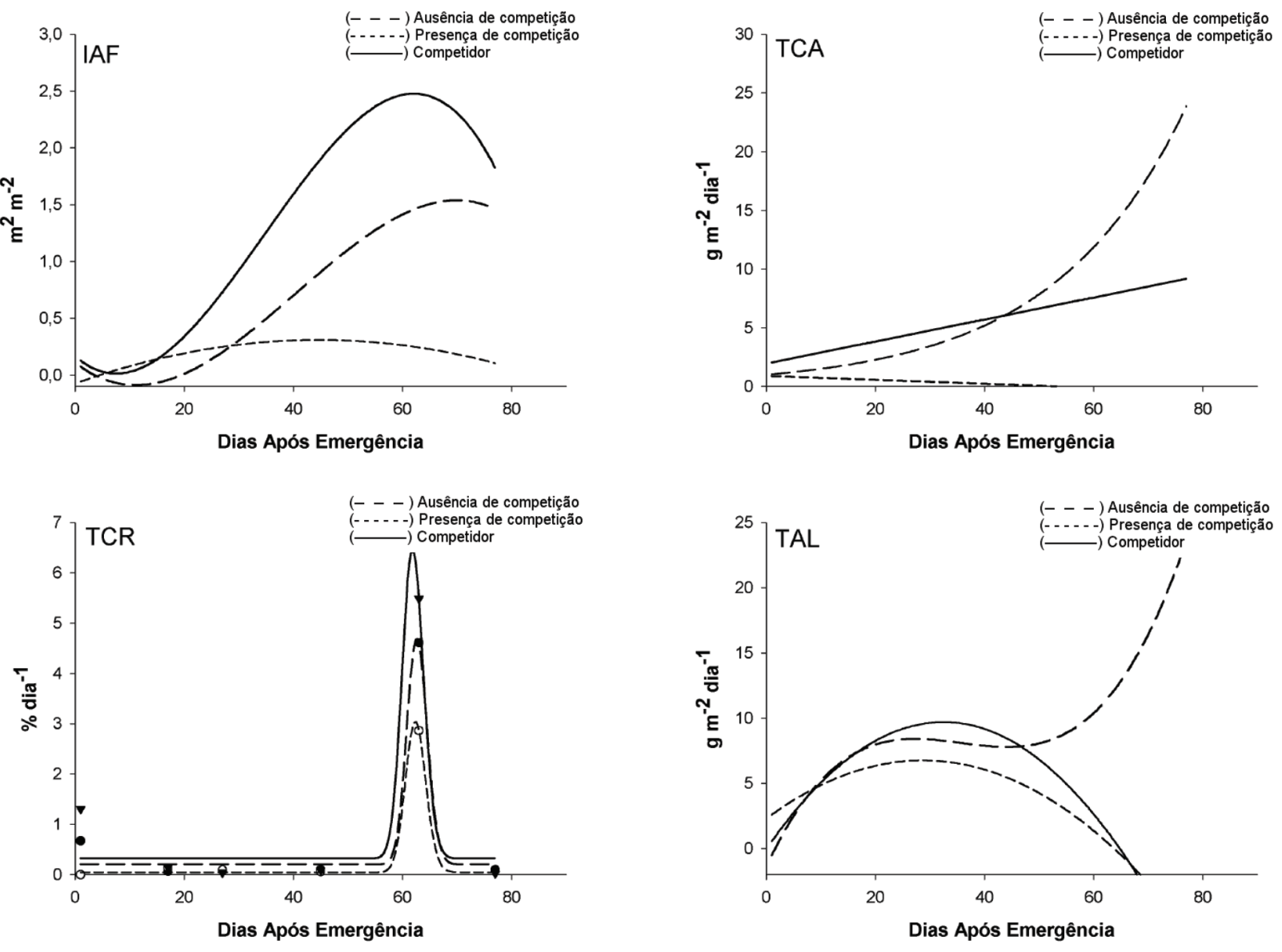

Figura 2: Índice de área foliar (IAF), taxas de crescimento absoluto (TCA) e relativo (TCR) e taxa de assimilação líquida (TAL) de crambe, na ausência e na presença de competição interespecífica e do competidor. Embrapa Agropecuária Oeste, Dourados-MS, 2011. 
tas cultivadas sob sombreamento excessivo: o libo foliar tende a ser menos espesso, de forma a maximizar o aproveitamento da radiação disponível (Gurevitch et al., 2009). Krug \& Fink (1991) afirmam ainda que a AFE aumenta com a temperatura, indicando que com metabolismo mais ativo as folhas tendem a expandir mais seu limbo foliar.

A AFE decresceu linearmente para todos os tratamentos (Figura 3). A cultura do crambe apresentou valores equivalentes de AFE entre os tratamentos, na ausência e na presença do competidor, com AFE de 268 e de 175 $\mathrm{cm}^{2} \mathrm{~g}^{-1}$ de folha, respectivamente, no início e no final do desenvolvimento (Figura 3). A AFE do competidor iniciou-se com valores ao redor de $205 \mathrm{~cm}^{2} \mathrm{~g}^{-1}$ de folha e, ao final do ciclo, equiparou-se à AFE do crambe (Figura 3), no mesmo ponto onde houve a coincidência de valores de MSF entre competidor e crambe na ausência de competição - entre 65 e 70 DAE (Figura 1). Este parâmetro indiretamente descreve uma relação entre a MSF e a AF, impossível de ser observada de outra forma.

Tironi et al. (2009), estudando a habilidade competitiva de plantas de arroz (Oryza sativa) contra capimarroz, não observaram alteração significativa da AFE do arroz com o aumento do sombreamento, com valores médios ao redor de $327 \mathrm{~cm}^{2} \mathrm{~g}^{-1}$ de folha. Ferreira et al. (2008) afirmam que sob competição a inibição ocasionada pelo competidor pode ocasionar mudanças mais severas na planta do que a disponibilidade de radiação solar, isoladamente. Krug \& Fink (1991) encontraram valores de AFE entre 240 e $360 \mathrm{~g} \mathrm{~m}^{-2}$ para o nabo forrageiro, em função do estresse ao qual a planta foi submetida no estudo. Para crambe, neste estudo, os valores situaram-se entre 170 e $268 \mathrm{~g} \mathrm{~m}^{-2}$, em função dos dias após a emergência da cultura e, de maneira geral, as folhas da cultura tornaram-se mais espessas (menor AFE), conforme a cultura desenvolveu-se (Figura 3).

A duração da área foliar (DAF) é outro parâmetro importante para se estimar o crescimento vegetal (Oliveira et al., 2006). O termo duração tem provocado equívocos, porque reflete uma ideia de tempo, conflitando quase sempre com o ciclo das espécies vegetais. Porém, a DAF expressa, em termos quantitativos, quanto tempo a planta mantém sua superfície assimilatória ativa (Sesták et al., 1971). Assim, neste trabalho, preservase a unidade completa da DAF $\left(\mathrm{m}^{2} \mathrm{~m}^{-2} \mathrm{dia}^{-1}\right)$ de forma similar a Aguiar-Netto et al. (2000), para enfatizar que,
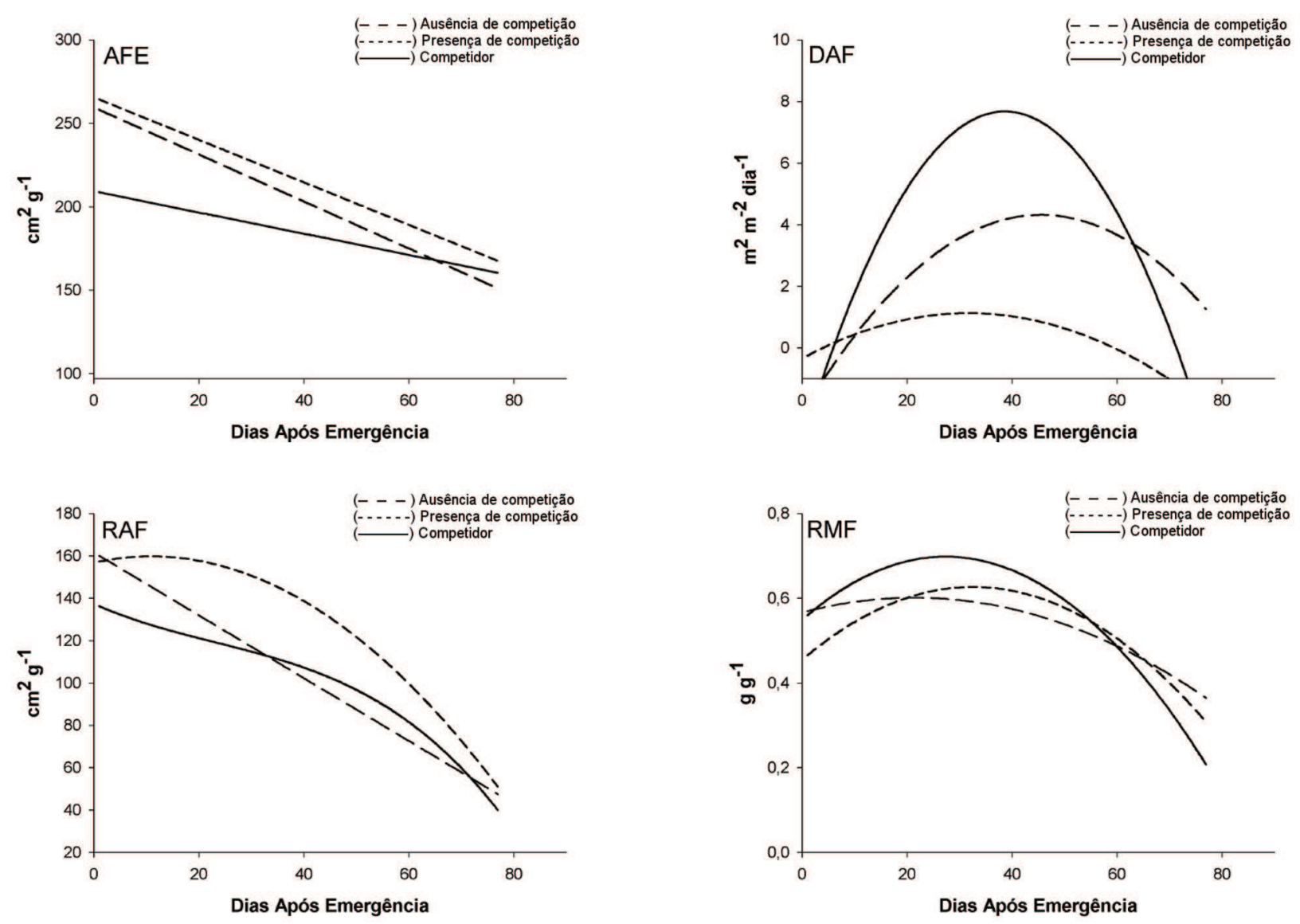

Figura 3: Área foliar específica (AFE), duração de área foliar (DAF), razão de área (RAF) e de massa (RMF) foliar de crambe, na ausência e na presença de competição interespecífica e do competidor. Embrapa Agropecuária Oeste, Dourados-MS, 2011. 
apesar de ser um índice, ela representa o tamanho relativo do aparelho fotossintético que permanece na planta em relação ao tempo (Oliveira et al., 2006).

A DAF foi descrita por modelo linear de $2^{\circ}$ grau para todos os tratamentos, com valores máximos de DAF de 4,0; 1,1 e 7,9 $\mathrm{m}^{2} \mathrm{~m}^{-2} \mathrm{dia}^{-1}$, aos 43, 30 e 39 DAE, respectivamente, para crambe sem competição, crambe sob competição e competidor (Figura 3).

É possível inferir também que os valores de DAF estão relacionados com os valores de TAL (Figura 2), por semelhança e correspondência de comportamento das regressões destas duas variáveis. Em essência, a TAL depende de dois grupos de fatores: aqueles relacionados com a planta e aqueles com o ambiente. Dentre os fatores relacionados com a planta, a TAL depende quase que diretamente, da DAF da planta, que por sua vez será uma das determinantes majoritárias da evolução do IAF, em condições normais de crescimento. Quanto a esta relação, Kmec et al. (1998) estabeleceram relação entre a DAF e a produtividade da cultura, embora tenham utilizado uma fórmula não padrão para o cálculo da DAF no referido trabalho. Em adição, sabe-se que a produtividade da cultura é função da sua fotossíntese líquida, que é expressa pela TAL.

A razão de área foliar (RAF) expressa a relação entre a área foliar da planta e o peso seco correspondente, sendo apropriada para avaliação dos efeitos genotípicos, climáticos e do manejo das comunidades vegetais (Oliveira et al., 2006). A RAF diminuiu para todos os tratamentos em função dos dias após a emergência. Embora para a cultura os valores no início e no final do ciclo tenham sido equivalentes, na ausência e na presença de competição, aos 40 DAE, o tratamento sob competição apresentou RAF de $135 \mathrm{~cm}^{2}$ de folha por grama de MST, enquanto o tratamento livre de competição apresentou $100 \mathrm{~cm}^{2}$ de folha por grama de MST (Figura 3). O comportamento da RAF do competidor equiparou-se ao do tratamento de crambe sem competição; no entanto, foi inferior a este até os 35 DAE e superior a este, a partir desse ponto (Figura 3).

Em estudo envolvendo a competição de nabo forrageiro com plantas daninhas, Channappagoudar et al. (2007) encontraram valores de RAF variando entre 150 e $320 \mathrm{~cm}^{2} \mathrm{~g}^{-1}$, respectivamente, quando a cultura desenvolveu-se na ausência e na presença de plantas daninhas. Neste estudo, os valores de RAF iniciaram-se ao redor de $150 \mathrm{~cm}^{2} \mathrm{~g}^{-1}$, sendo reduzidos para cerca de $60 \mathrm{~cm}^{2} \mathrm{~g}$ ${ }^{1}$, aos 70 DAE da cultura e do competidor (Figura 1). Em outras palavras, isto significa dizer que a dimensão do aparato fotossintético foi gradativamente reduzida, conforme a planta avançou no desenvolvimento, provavelmente por causa do estresse hídrico ao qual a cultura foi submetida, por escassez de chuvas até os 60 DAE. O mesmo comportamento linear decrescente da RAF foi observado por Krug \& Fink (1991), para o nabo forrageiro, em função do aumento da radiação incidente sobre a cultura: quanto maior a radiação menor a RAF. Isto também está de acordo com o previamente discutido para a AFE.

A razão de massa foliar (RMF) representa a relação entre a biomassa seca das folhas e a biomassa seca total da planta (Tironi et al., 2009), sendo descrita neste trabalho por modelo linear de $2^{\circ}$ grau para todos os tratamentos, com valores máximos de RMF de 0,58; 0,61 e $0,70 \mathrm{~g} \mathrm{~g}^{-1}$, aos 18,30 e $24 \mathrm{DAE}$, respectivamente para crambe sem competição, crambe sob competição e competidor (Figura 3). Krug \& Fink (1991) encontraram valores de RMF 0,43 e 0,76 $\mathrm{g} \mathrm{g}^{-1}$, para o nabo forrageiro, independentemente da quantidade de radiação disponível para a cultura. Esses valores são condizentes com os obtidos para a cultura do crambe neste trabalho.

A RMF apresentou comportamento similar ao da DAF, que, por sua vez, é um dos determinantes majoritários da TAL. Isto significa que a DAF, além da TAL, provavelmente também é uma das responsáveis pela RMF, ou seja, a relação de massa da planta distribuída em colmos e em folhas (Aspiazú et al., 2008); quanto maior esta relação, maior a proporção da massa seca da planta que foi depositada em folhas (responsáveis majoritárias pela fotossíntese), em vez de ser depositada em colmos (crescimento da planta em altura).

\section{CONCLUSÕES}

A cultura do crambe apresenta baixo potencial competitivo, em comparação a aveia, e o efeito da competição é mais severo até os 60 - 70 DAE da cultura. Além disso, pode-se inferir que o desempenho da cultura em condições de campo é diretamente descrito pela Taxa de Assimilação Líquida (TAL), que, por sua vez, é altamente influenciada pela Duração da Área Foliar (DAF) e pela Razão de Massa Foliar (RMF), parâmetros que descrevem com maiores critérios a dinâmica de acúmulo de massa seca e a correspondente expansão da área foliar da planta.

\section{REFERÊNCIAS}

Aguiar-Netto AO, Rodrigues JD \& Pinho SZ (2000) Análise de crescimento na cultura da batata submetida a diferentes lâminas de irrigação. Pesquisa Agropecuária Brasileira, 35:901-907.

Aspiazú I, Concenço G, Galon L, Ferreira EA \& Silva AF (2008) Relação colmos/folhas de biótipos de capim-arroz em condição de competição. Revista Trópica: Ciências Agrária e Biológicas, 22:22-30.

Baez O (2007) "Crambe” a grande aposta das pesquisas em Mato Grosso do Sul. Disponível em: <http://www.biodieselbr.com/noticias/emfoco/crambe-grande-aposta-pesquisas-mato-grosso-sul.htm $>$. Acessado em 03 de fevereiro de 2012. 
Channappagoudar BB, Koti RV, Biradar NR \& Bharmagoudar TD (2007) Influence of herbicides on growth parameters and yield in radish. Karnataka Journal of Agricultural Science, 20:710-714.

Chandranath HT (2006) Investigations on nutrient management and planting geometry in companion cropping of sunflower (Helianthus annuus) and ashwagandha (Wnithania somnifera). Tese de doutorado. University of Agricultural Sciences, Dharwad. 191p.

Concenço G, Aspiazu I, Ferreira EA, Galon L \& Silva AF (2012) Physiology of crops and weeds under biotic and abiotic stresses. Disponível em: < http://www.intechweb.org>. Acessado em: 15 de fevereiro de 2012.

Domingos VD, Martins D, Costa NV, Marchi SR \& Rodrigues-Costa AC (2011) Alocação de biomassa de Brachiaria subquadripara sob diferentes concentrações de N, P e K. Planta Daninha, 29:25-36.

EMBRAPA - Empresa Brasileira de Pesquisa Agropecuária (1999) Sistema brasileiro de classificação de solos. Rio de Janeiro, Centro Nacional de Pesquisa de Solos. 412p.

Ferreira EA, Concenço G, Aspiazu I, Silva AA, Galon L, Silva AF, Ferreira FA \& Noldin JA (2008) Crescimento de biótipos de capim-arroz em condição de competição. Planta Daninha, 26:799-805.

Gardner PF, Pearce RB \& Mitchell RL (1985) Physiology of crop plants. Iowa, Iowa State University Press. 337p.

Gurevitch J, Scheiner SM \& Fox GA (2009) Ecologia vegetal. Porto Alegre, Artmed. 574p.

Kmec P, Weiss MJ, Milbrath LR, Schatz BG, Hanzel J, Hanson BK \& Eriksmoen BK (1998) Growth analysis of crambe. Crop Science, 38:108-112.

Krug H \& Fink M (1991) Transferability of plant-climate-reaction parameters (growth chambers, greenhouses and fields). Biotronics, 20:31-42.
Larcher W (2004) Ecofisiologia Vegetal. São Carlos, Rima. 531p.

Massey FJ (1951) The Kolmorov-Smirnov test for goodness of fit. Journal of the American Statistical Association, 46:68-78.

Merrill SD, Tanaka DL \& Hanson JD (2002) Root length growth of eight crop species in haplustoll soils. Soil Science Society of America Journal, 66:913-923.

Monteiro JMG (2007) Plantio de oleaginosas por agricultores familiares do semi-árido nordestino para produção de biodiesel como uma estratégia de mitigação e adaptação às mudanças climáticas. Tese de doutorado. Universidade Federal do Rio de Janeiro, Rio de Janeiro. $315 \mathrm{p}$

Oliveira LM, Paiva R, Alvarenga AA \& Nogueira RC (2006) Análise do crescimento. In: Paiva R \& Oliveira LM (Eds.) Fisiologia e produção vegetal. Lavras, UFLA. p.93-104.

Oliveira RA, Daros E, Zambon EJLC, Weber H, Ido HOT, BespalhokFilho JC, Zuffellato-Ribas KC \& Silva DKT (2007) Área foliar em três cultivares de cana-de-açúcar e sua correlação com a produção de biomassa. Pesquisa Agropecuária Tropical, 37:71-76.

R Development Core Team. (2012) R: A language and environment for statistical computing. Disponível em: 〈http://www.R-project.org/〉. Acessado em: 15 de fevereiro de 2012.

Sesták Z, Catsky J \& Jarvis PG (1971) Plant photosynthetic production: manual of methods. The Hague, W Junk Publishers. 555p.

Thornley JHM (1976) Mathematical models in plant physiology. London, Academic Press. 318p.

Tironi SP, Galon L, Concenço G, Ferreira EA, Silva AF, Aspiazú I, Ferreira FA, Silva AA \& Noldin JA (2009) Habilidade competitiva de plantas de arroz com biótipos de capim-arroz resistente ou suscetível ao quinclorac. Planta Daninha, 27:257-263. 